\title{
Neural Substrates of Visual Stimulus-Stimulus Association in Rhesus Monkeys
}

\author{
Elisabeth A. Murray, David Gaffan, and Mortimer Mishkin \\ Laboratory of Neuropsychology, National Institute of Mental Health, Bethesda, Maryland 20892 and Department of \\ Experimental Psychology, Oxford University, Oxford, UK
}

Rhesus monkeys learned 10 visual stimulus-stimulus association, or paired associates. They then received bilateral removals of either the amygdaloid complex and underlying cortex, the hippocampal formation and underlying cortex, or both combined, or they were retained as unoperated controls. After surgery or rest, the monkeys were tested for their retention of the preoperatively learned set of paired associates, as well as for their ability to learn new associations of the same type. Both unoperated controls and hippocampectomized monkeys relearned the preoperatively trained set of paired associates almost immediately. By contrast, monkeys with amygdala removals were moderately retarded in relearning, and monkeys with combined amygdala and hippocampal ablations were severely retarded. When confronted with new sets of visual stimuli, monkeys with amygdala removals or hippocampal removals learned new sets of paired associates at the same rate as the controls, whereas monkeys with the combined ablation were again profoundly retarded. Only one monkey with the combined lesion was able to learn new stimulus-stimulus associations to criterion, and then only after extensive training, despite the ability of all three animals in this group to perform delayed matching-to-sample with the same stimuli and the same intratrial delays as those used in the paired associate task. At the end of the main experiment, two of the unoperated controls received bilateral ablations of the rhinal cortex. These monkeys showed the same level of difficulty in learning new paired associates as the animals in the main experiment that had received the combined amygdala plus hippocampal ablations. The results implicate the medial temporal lobe, and particularly the rhinal cortex, in the formation of stimulus-stimulus associative memories.

[Key words: memory, amygdala, hippocampus, entorhinal cortex, perirhinal cortex, amnesia]

Research in macaques suggests that at least three different memory mechanisms exist in the medial temporal lobe. The amygdala and the hippocampus mediate two different kinds of associative memory. Removal of the amygdala plus subjacent

\footnotetext{
Received Oct. 21, 1992; revised Apr. 21, 1993; accepted Apr. 29, 1993.

This work was supported by the North Atlantic Treaty Organization (NATO Grant 0184/87). We thank D. Ivkovich and S. Angeli for assisting with the behavioral testing, and T. Fobbs, W. Hadfield, and B. Wood for help with the histology.

Correspondence should be addressed to Dr. Elisabeth A. Murray, Laboratory of Neuropsychology, National Institute of Mental Health, Building 49, Room 1B80, Bethesda, MD 20892.

Copyright (C) 1993 Society for Neuroscience $0270-6474 / 93 / 134549-13 \$ 05.00 / 0$
}

cortex impairs cross-modal and stimulus-reward association memory (Spiegler and Mishkin, 1981; Murray and Mishkin, 1985; Gaffan and Harrison, 1987; Gaffan et al., 1988; Gaffan and Murray, 1990; Baylis and Gaffan, 1991), whereas either removal of the hippocampus plus subjacent cortex or fornix transection produces impairments in spatial associative memory (Gaffan and Saunders, 1985; Parkinson et al., 1988; Gaffan and Harrison, 1989; Angeli et al., 1993). Recognition memory, as tested by delayed matching or nonmatching-to-sample, is a third mechanism separable from these two associative memory mechanisms. Early results indicated that a severe impairment in delayed nonmatching-to-sample was produced only by combined ablation of the amygdala plus the hippocampus, and not by either of these ablations alone (Mishkin, 1978). More recent experiments have shown, however, that the effect of that combined ablation on recognition memory may be attributable to the inclusion of the rhinal cortex in the combined ablation (Horel et al., 1987; Zola-Morgan et al., 1989). Indeed, selective rhinal cortex ablation, leaving the hippocampus and amygdala intact, also produces a severe impairment in recognition memory (Gaffan and Murray, 1992; Meunier et al., 1993).

The purpose of the present experiment was to investigate further these dissociations of memory function revealed by hippocampectomy, amygdalectomy, and both combined. We tested the effects of these ablations in a type of associative memory that has not previously been investigated in ablation experiments, namely, visual stimulus-stimulus associative memory.

Gaffan and Bolton (1983) showed that rhesus monkeys could learn to associate a visual stimulus with another visual stimulus, independently of the association of each stimulus with food reward. The monkeys in Gaffan and Bolton's experiments displaced three-dimensional objects that were placed over wells in a Wisconsin Gencral Test Apparatus, and learned to associate each displaced object with the visual properties of a further object that was found in the well underneath the displaced object. The task we used in the present experiment was designed on the assumption that monkeys would similarly be able to associate visual stimuli with each other when the stimuli were two-dimensional patterns displayed on a monitor screen.

In the task used in the main part of the experiment (illustrated in the right panel in Fig. 1) the monkeys learned sets of visualvisual paired associates. Each pair consisted of two colored shapes that could be displayed either together, forming a single compound stimulus, or separately as the parts of that stimulus. For example, one compound stimulus (shown in Fig. 1) was a blue "v" superimposed on a red "F". The parts of this stimulus appeared as sample and choice stimuli in the experimental task. If " $v$ " was the sample, then " $F$ " was the correct choice at the 


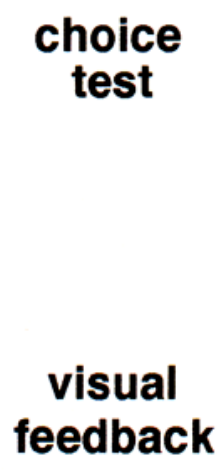

\section{STAGE}

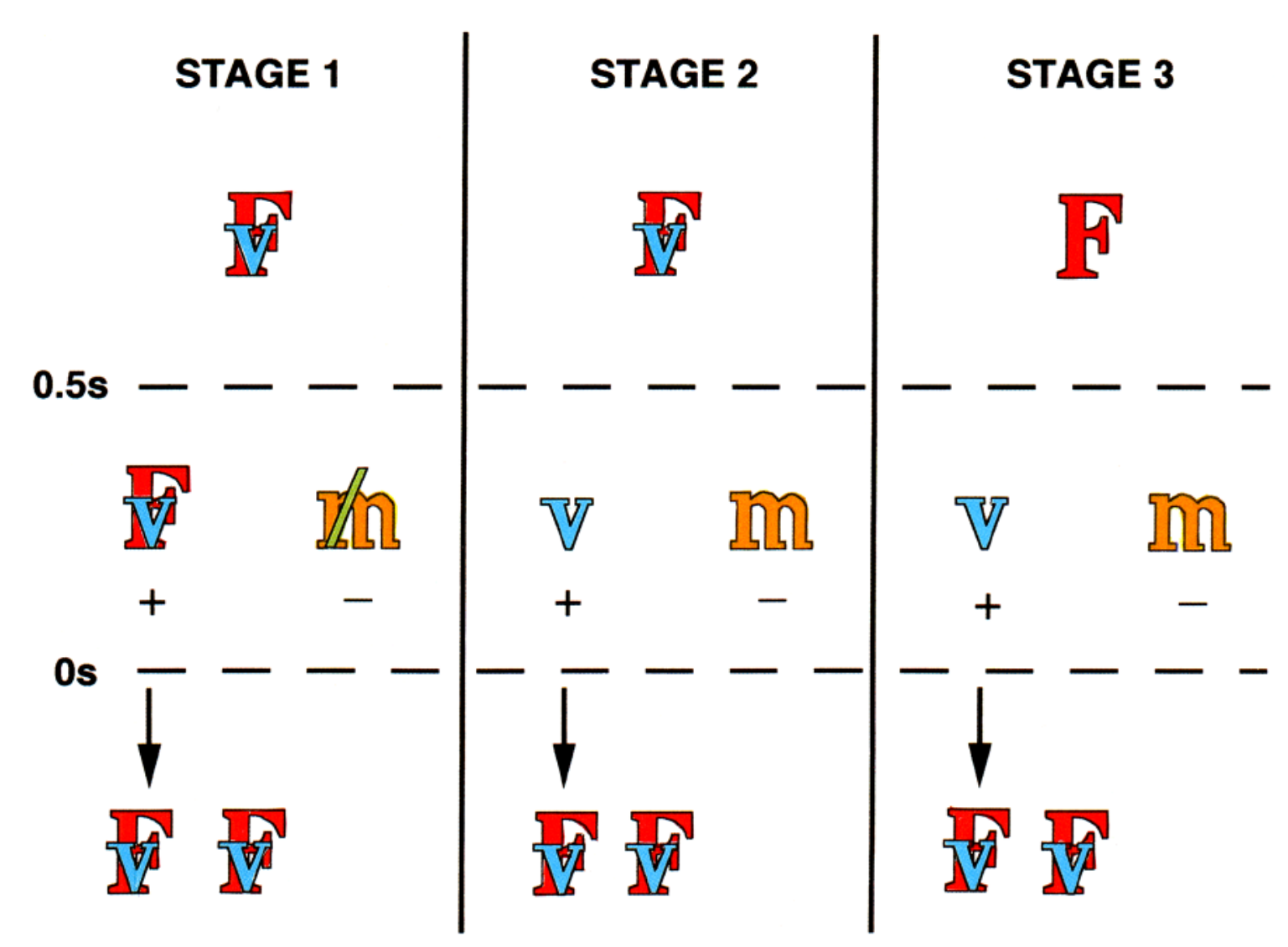

Figure 1. A schematic diagram of the stages of preoperative training. Shown for each stage is a typical trial consisting of sample presentation, choice test, and visual feedback for correct responses. STAGE 1 is delayed matching-to-sample, STAGE 2 is delayed matching of whole-to-part, and $S T A G E 3$ is matching of one part to the other. Note that the visual feedback for a correct response at each stage consists of the reappearance of the whole, compound stimulus in both the center and one side location on the monitor screen.

subsequent choice test; similarly, if " $F$ " was the sample then " $v$ " was the correct choice at the choice test. However, if either "v" or "F" was presented as a choice test stimulus without the prior presentation of the other part ("F" or " $v$ ", respectively) as the sample, it was the incorrect choice at that choice test, the other test stimulus being the correct paired associate for the sample on that trial. Incorrect choices immediately blanked the screen and initiated an intertrial interval without food reward. Correct choices at choice tests were rewarded with food, but they alsc produced a visual feedback on the screen that consisted of the whole, compound stimulus made up of the constituent parts, sample plus choice, in this case the " $v$ " superimposed on the "F." Our purpose in providing this compound stimulus feedback was to facilitate the learning of the association between the two constituent parts, each of which can be associated with the whole. The monkeys learned several different sets of visualvisual associations of this kind.

The first set of visual-visual associations was taught preoperatively. The monkeys were then divided into four groups: an unoperated control group, a group receiving removals of the amygdala plus underlying cortex, a group receiving removals of the hippocampus plus underlying cortex, and a group receiving the two removals in combination. After the surgical operations had been performed, the animals were tested for retention of the preoperatively acquired set of paired associates (set 1). They were next tested for the ability to acquire two new sets (set 2 and set 3).

Finally, the monkeys were tested for their ability to learn a control set (set 4), which was presented in the same way as the others except that they were not provided the same opportunity to form part-whole, visual-visual associations as described above. In the control set of stimuli, for example, a purple "C" as sample indicated that a yellow "k" was the correct stimulus to choose, but the animals never saw the compound consisting of the yellow "k" superimposed on the purple "C." This control procedure was included to determine whether, in the earlier sets, the animals had indeed learned part-whole, visual-visual associations as a result of the whole-stimulus feedback that had been provided. If so, it was expected that learning to choose correctly in the control procedure (set 4) would proceed more slowly than it had in the main part of the experiment (sets 13).

The comparisons among the three groups with surgical ablations allowed us to test rival hypotheses about the nature of the memory functions of structures in the medial temporal lobe. As outlined above, previous experiments have shown that the 
amygdala and hippocampus make selective contributions to associative memory in monkeys. It is unclear, however, whether either of these structures contributes critically to intramodal stimulus-stimulus associative learning of the type tested here. On the one hand, if the amygdala is critical for cross-modal stimulus-stimulus associations (Murray and Mishkin, 1985), then perhaps it is also necessary for intramodal stimulus-stimulus associations. On the other hand, if the hippocampus and fornix are critical for associating visual stimuli with the visual places or scenes in which they appear (Parkinson et al., 1988; Gaffan and Harrison, 1989), then perhaps the hippocampus is necessary as well for the intramodal, visual-visual associations of the type tested here.

Given the recent evidence cited above regarding the importance of rhinal cortex for visual recognition memory, we thought it important to assess its possible contribution to the present task as well. Accordingly, at the end of the main experiment, two of the normal control animals received rhinal cortex ablations. They were tested postoperatively for retention of the first set of preoperatively acquired stimulus-stimulus associations and also for their ability to learn a new set of stimulusstimulus associations that had not been presented in the main experiment.

\section{Materials and Methods}

\section{Subjects}

The subjects were 13 experimentally naive rhesus monkeys (Macaca mulatta) ranging in weight from 3.2 to $6.0 \mathrm{~kg}$ at the time of surgery (or time of rest period for the controls). The animals were housed singly in cages and fed a diet of monkey chow (Purina) supplemented with fruit. Water was always available.

\section{Surgery}

Anesthesia was induced with ketamine hydrochloride $(10 \mathrm{mg} / \mathrm{kg})$ and maintained with sodium pentobarbital (approximately $25-30 \mathrm{mg} / \mathrm{kg}$ ). Supplemental doses of pentobarbital were given to effect intravenously, and the animals received $0.45 \%$ sodium chloride plus $5 \%$ dextrose drip. Aseptic procedures were employed. Heart rate, respiration rate, and body temperature were monitored throughout the procedure. Cranial openings were made in the appropriate location and the dura was reflected. Then one-stage, bilateral removals of either the amygdaloid complex, the hippocampal formation, both in combination, or the rhinal cortex were achieved by direct aspiration of tissue with the aid of an operating microscope. When the removal was completed, the wound was closed in anatomical layers with silk sutures. For $1 \mathrm{~d}$ before surgery and for 1 week after, the animals received a treatment regimen of dexamethasone sodium phosphate and gentamicin sulfate to reduce inflammation and protect against infection, respectively. For $3 \mathrm{~d}$ after surgery, the monkeys also received acetominophen $(40 \mathrm{mg})$ as an analgesic.

Amygdala removals were made via a supraorbital approach. The frontal lobe was elevated with a brain spoon and the rhinal sulcus on the rostral surface of the temporal lobe was identified. The temporal lobe medial to the rhinal sulcus was entered with a small-gauge sucker and the tissue aspirated. The boundaries of the lesion were the rostral face of the hippocampus, caudally; the basal forebrain tissue level with the top of the rostral face of the hippocampus, dorsally; and the fundus of the rhinal sulcus and white matter of the temporal stem, laterally. The lesion thus included the pyriform and periamygdaloid cortex, as well as the anterior portion of the entorhinal cortex immediately subjacent to the amygdala.

Hippocampal removals were made via a supralabyrinthine approach. The posterior part of the inferior temporal cortex was elevated with a brain spoon, and the occipitotemporal sulcus was identified. Then cortex on the ventral surface of the brain between the sulcus and the brainstem was removed. The temporal horn of the lateral ventricle was then entered and the body of the hippocampus was transected at approximately the middle of its anteroposterior extent. Finally, the removal of the hippocampal formation was extended rostrally and then caudally until it was complete. The boundaries of the lesion consisted of the fundus of the occipitotemporal sulcus, ventrolaterally; the amygdala, rostrally; the brainstem, medially; and the roof of the ventricle, dorsally and laterally. The lesion thus included the hippocampal formation (hippocampus proper, dentate gyrus, and subicular complex), the posterior portion of the entorhinal cortex, and the cortex of the parahippocampal gyrus.

The combined ablation of the amygdala and hippocampus was accomplished by combining the two procedures above in the order described.

Rhinal cortex ablations were made via a cranial opening extending from the orbit, rostrally, to about the level of the external auditory meatus, caudally. Two approaches were used in each hemisphere. First, the frontal lobe was elevated with a brain spoon, the rhinal sulcus was visualized, and then the tissue lining both banks of the rostral half of the rhinal sulcus was aspirated as well as approximately $2 \mathrm{~mm}$ of tissue both medial and lateral to it. 'The animal's head was then turned approximately $120^{\circ}$ from vertical so that the temporal lobe could be more easily retracted from the temporal fossa. The caudal half of the rhinal sulcus was then visualized, and the lesion of both banks of the rhinal sulcus was extended posteriorly, from the point to which it had been carried in the first approach to the caudal end of the rhinal sulcus, again including both banks of the sulcus as well as about $2 \mathrm{~mm}$ of cortex lateral to it. In addition, the tissue extending 5-6 mm medial to the caudal half of the rhinal sulcus was aspirated in an attempt to include all the entorhinal cortex.

\section{Histology}

Upon completion of the experiment, the monkeys were given an overdose of barbiturates and perfused through the heart with normal saline followed by $10 \%$ buffered formalin. The brains were removed, photographed, embedded in celloidin, and sectioned at $25 \mu \mathrm{m}$ in the coronal plane. Every 10th or 20th section was stained with thionin, mounted, and coverslipped. Figures 2-5 show a series of sections through the lesions from one animal in each of the surgical groups.

The ablations in the three monkeys receiving bilateral amygdalectomy were essentially as intended. All the ablations were complete, although varying degrees of damage to the adjacent part of the tail of the caudate nucleus were evident in all three as well. In A-1, this damage was limited to $1 \mathrm{~mm}$ on the left, whereas in A-3, the damage was bilateral and complete for $4 \mathrm{~mm}$, and partial for an additional $8 \mathrm{~mm}$. Case A-2 sustained damage to the tail of the caudate nucleus and to a small adjacent portion of the ventral putamen for a distance of $5 \mathrm{~mm}$ on the left and $3 \mathrm{~mm}$ on the right, the damage to the tail continuing an additional $6 \mathrm{~mm}$ on the right. Finally, A-3 sustained bilateral perirhinal damage limited to the rostralmost $2 \mathrm{~mm}$ of the lateral bank of the rhinal sulcus.

The hippocampal removals in all four animals were complete or nearly so. In one monkey $(\mathrm{H}-2)$, there was sparing of $1 \mathrm{~mm}$ of the posteromedial part of the uncus on the left, and in another $(\mathrm{H}-3)$, there was a similar amount of sparing of the most caudal extent of the left hippocampus. As for inadvertent damage, two monkeys sustained small infarcts in the right inferior temporal cortex, involving the lateral bank of the occipitotemporal sulcus (in $\mathrm{H}-2$ ), or tissue just lateral to this sulcus (in $\mathrm{H}-4$ ).

The ablations in the three monkeys receiving bilateral removals of the amygdaloid complex and hippocampal formation were also complete. Like the amygdalectomized monkeys, all three cases sustained inadvertent damage to the tail of the caudate nucleus: AH-1 for a distance of about $13 \mathrm{~mm}$ on the left and $3 \mathrm{~mm}$ on the right, AH-2 for a distance of $12 \mathrm{~mm}$ on the left, and AH-3 for about $10 \mathrm{~mm}$ bilaterally. In $\mathrm{AH}-1$, there was also a small amount of damage to the ventral putamen on the left. All three monkeys also sustained a small amount of damage to the posterior inferior temporal cortex (unilaterally in AH-1 and bilaterally in the others) where this tissue had been elevated in order to gain access to the hippocampus, and two sustained slight damage to the portion of perirhinal cortex located in the lateral bank of the rhinal sulcus (for a distance of $2 \mathrm{~mm}$ on the right and about $8 \mathrm{~mm}$ on the left in $\mathrm{AH}-1$ and $\mathrm{AH}-3$, respectively).

The ablations in both monkeys with rhinal cortex lesions unintentionally spared the most medial portion of the entorhinal cortex at the level of the posterior amygdala, unilaterally in $\mathrm{Rh}-1$ and bilaterally in $\mathrm{Rh}-2$. Conversely, the lesion extended more laterally than intended to include inferior temporal cortex nearly to the anterior middle temporal sulcus unilaterally in Rh-2 and bilaterally in Rh-1. Finally, $R h-2$ sus- 

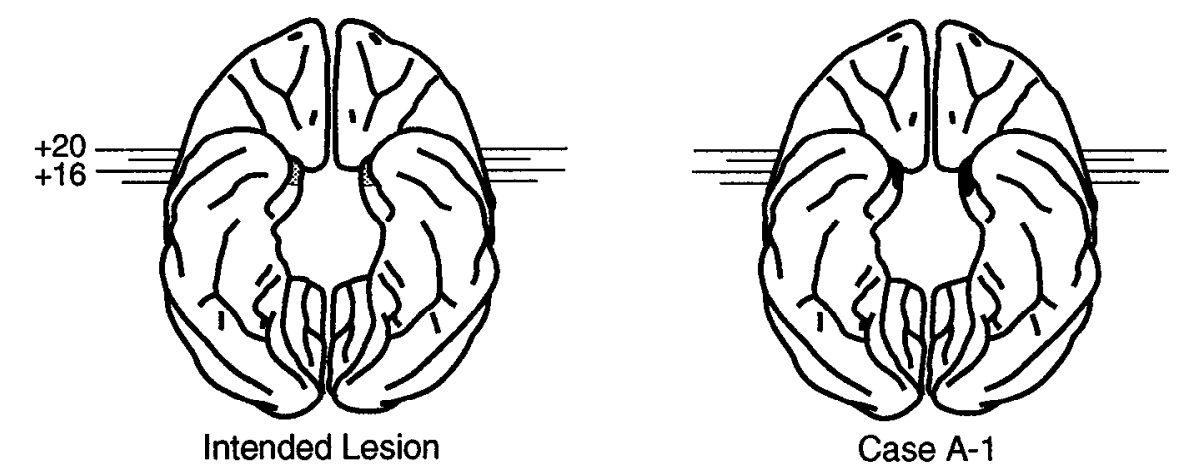

Case A-1
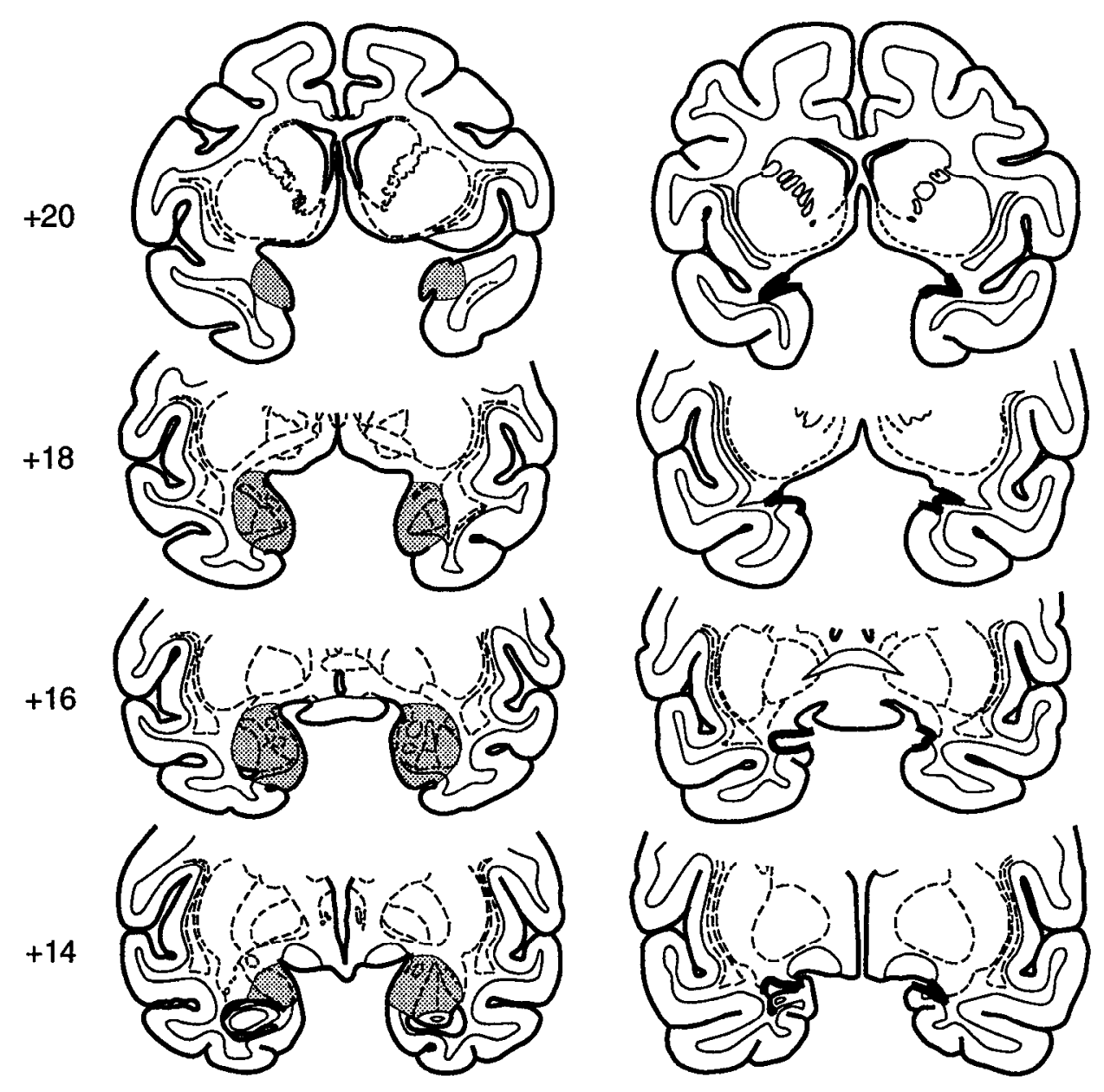

Figure 2. Surface reconstruction of a lesion on a standard ventral view of a macaque brain (top) and coronal sections through the lesion (below) for one monkey with an amygdala ablation $(A$ 1). The intended lesion (left column) is indicated by the shaded regions on the ventral view and coronal sections of a normal brain. Actual lesion in $A-1$ is shown in black on the ventral view and by the heavy black lines in the coronal sections. For ease in visual matching of coronal sections to the ventral reconstructions, the ventral view has been reversed (i.e., the left hemisphere is shown at left) in this and the following three figures. Numerals indicate the distance in millimeters from the interaural plane ( 0$)$.

tained slight damage to the ventral portion of the lateral nucleus of the amygdala on the right.

\section{Test apparatus}

A computer-controlled test apparatus was used. The system was adapted from Gaffan et al. (1984) and consisted of an IBM XT computer connected to both a color monitor fitted with a touch screen (Microtouch Systems, Inc., Woburn, MA) and an automatic pellet dispenser (BRS/ LVE, Laurel, MD). Visual stimuli were colored two-dimensional figures generated by the computer and displayed on the color monitor. A "whole" or compound stimulus consisted of two ASCII characters of different sizes (maximum height, approximately $50 \mathrm{~mm}$ ) and different colors, one superimposed on the other (e.g., a small green " 2 " on a larger white " $x$ "). The two "parts" of the whole stimulus (e.g., the " 2 " or the " $x$ ") could each be displayed separately. The screen was divided into three rectangular touch-sensitive zones aligned in a horizontal array; one was in the center of the screen, and the other two were $75 \mathrm{~mm}$ to the left and right of center. Stimuli could appear in any of these three zones. The front of the test cage, which was $210 \mathrm{~mm}$ from the screen, contained vertical bars spaced $50 \mathrm{~mm}$ apart, allowing the monkeys easy access to the monitor. A food cup, which received rewards via a tube connected to the pellet dispenser, was located immediately below the center of the screen. Rewards consisted of single $190 \mathrm{mg}$ banana-flavored pellets (Noyes, Inc., Lancaster, NH).

\section{Preliminary training}

Monkeys were shaped to touch the monitor screen in two steps, which together werc usually completed in a total of about 5 or $6 \mathrm{~d}$. First, they were given sessions in which visual stimuli appeared in the center of the screen according to a $2 \mathrm{~min}$ variable interval schedule. The stimulus remained on the monitor screen for $10 \mathrm{sec}$, after which a food reward was delivered and the stimulus disappeared, terminating the trial. A touch of the stimulus before the end of the $10 \mathrm{sec}$ display period resulted in immediate delivery of food and termination of the trial. During these sessions, all the monkeys touched some of the stimuli on the screen spontaneously, and, after two sessions with a minimum of two responses (touches) each, animals were given the second step of shaping. As in the first step, visual stimuli appeared in the center of the screen. Now, 


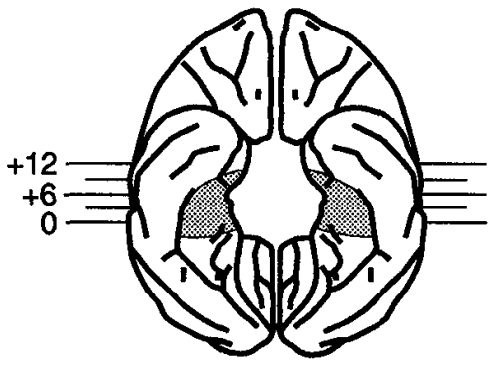

Intended Lesion

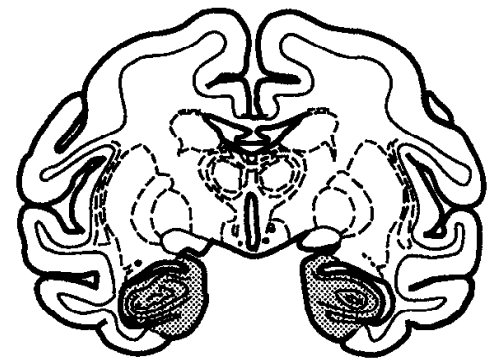

$+9$

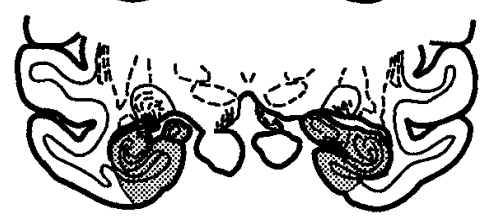

$+6$

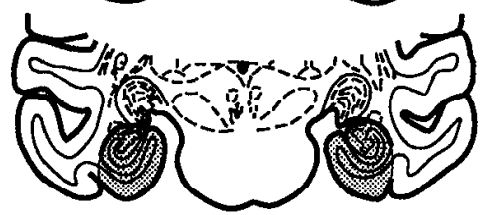

$+3$

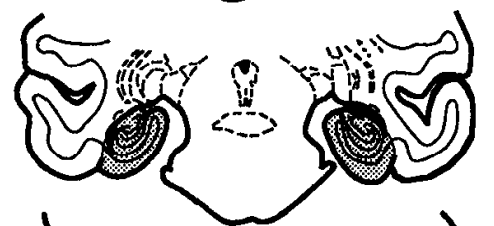

0

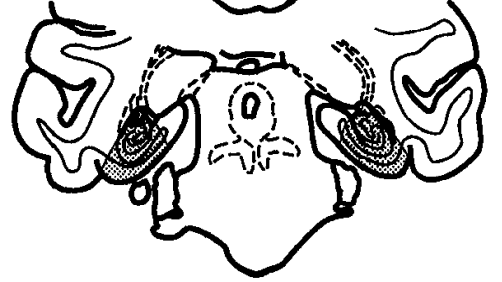

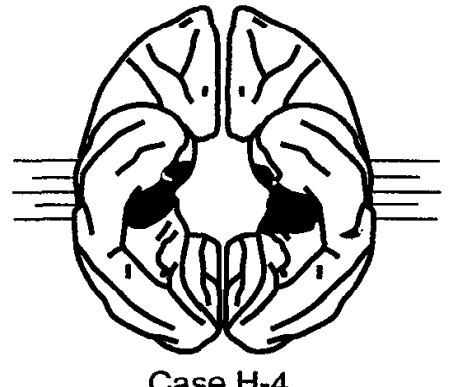

Case $\mathrm{H}-4$
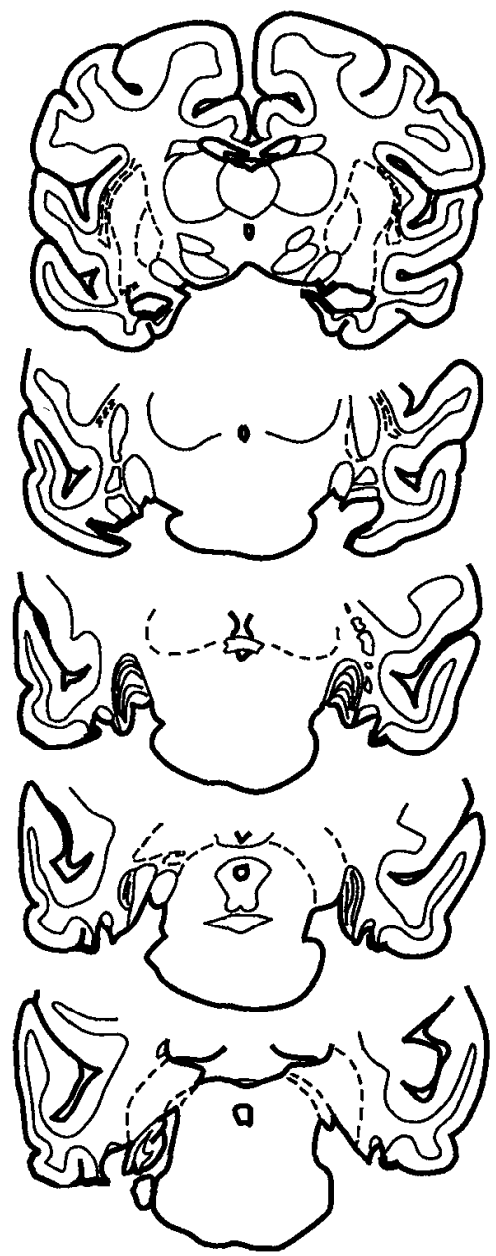

Figure 3. Ventral surface reconstruction (top) and coronal sections through the lesion (below) for one monkey with a hippocampal ablation $(H-4)$. The intended removal is shown in the left col$u m n$. Conventions are as in Figure 2. however, delivery of the food reward was contingent on the animal's response to the stimulus. Either a touch of the stimulus or failure to respond within $30 \mathrm{sec}$ terminated the trial. Trials were separated by 30 sec. When each monkey had completed 49 out of the 50 trials per session for 2 consecutive days, it began formal training.

\section{Preoperative training}

The monkeys were trained in a series of stages, rather than in a single (final) stage, with the aim of speeding their acquisition of a fixed set of stimulus-stimulus associations, or paired associates.

Stage 1. Monkeys were trained on delayed matching-to-sample with session-unique stimuli. A typical trial from this stage is illustrated in the left panel of Figure 1. A compound sample stimulus appeared in the center of the screen, and the monkeys were required to touch the stimulus, at which time it disappeared. One-half second later, the sample plus a new compound stimulus appeared on the sides of the screen, in random left-right order. If the monkey touched the matching stimulus, it received immediate delivery of a food pellet plus visual feedback. The feedback in this and the subsequent stages consisted of the sample reappearing for $1 \mathrm{sec}$ both in the center and on the side of the screen that had been touched, as shown in Figure 1. An incorrect response resulted in a blank screen. A total of 160 compound stimuli were paired randomly to make one test session consisting of 80 trials. Although each stimulus appeared in only one trial per day, and was therefore unique within each session, the same stimuli were used across days. Trials were separated by $7 \mathrm{sec}$; any touch of the blank screen during the intertrial interval reset the interval. Criterion was set at a mean of $90 \%$ correct responses for 5 consecutive days.

After attaining criterion, monkeys were transferred to three more versions of delayed matching that used an increasingly smaller subset of the 160 stimuli. The first employed 40 stimuli randomly paired within five 20-trial blocks per session. The second employed 20 stimuli randomly paired in ten 10-trial blocks per session. The third and final version employed 10 stimuli randomly paired in ten 10-trial blocks per session. In this final version each compound stimulus appeared once as a sample and once again as a distractor in each block of trials. For all three versions with the reduced stimulus sets, the delays and intertrial intervals were the same as those used in the original version of delayed matching-to-sample, but the rate of training was increased to 100 trials 


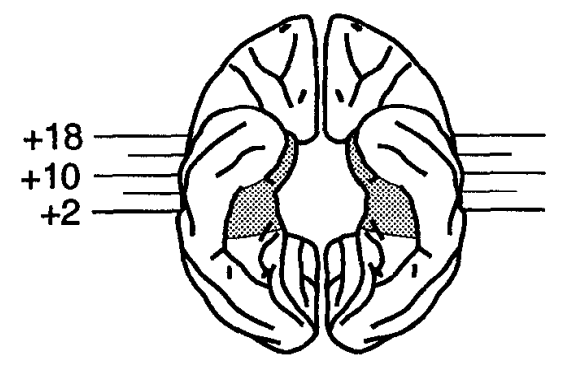

Intended Lesion
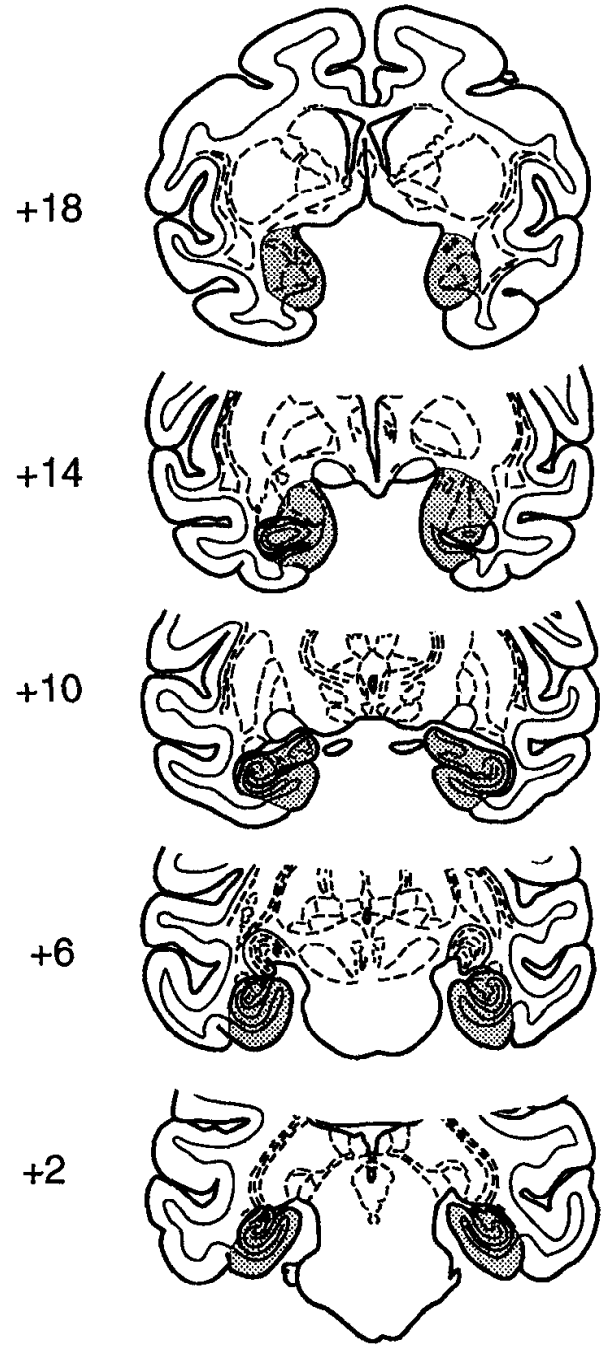

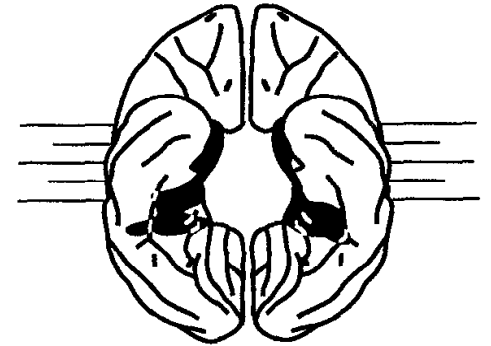

Case $\mathrm{AH}-3$
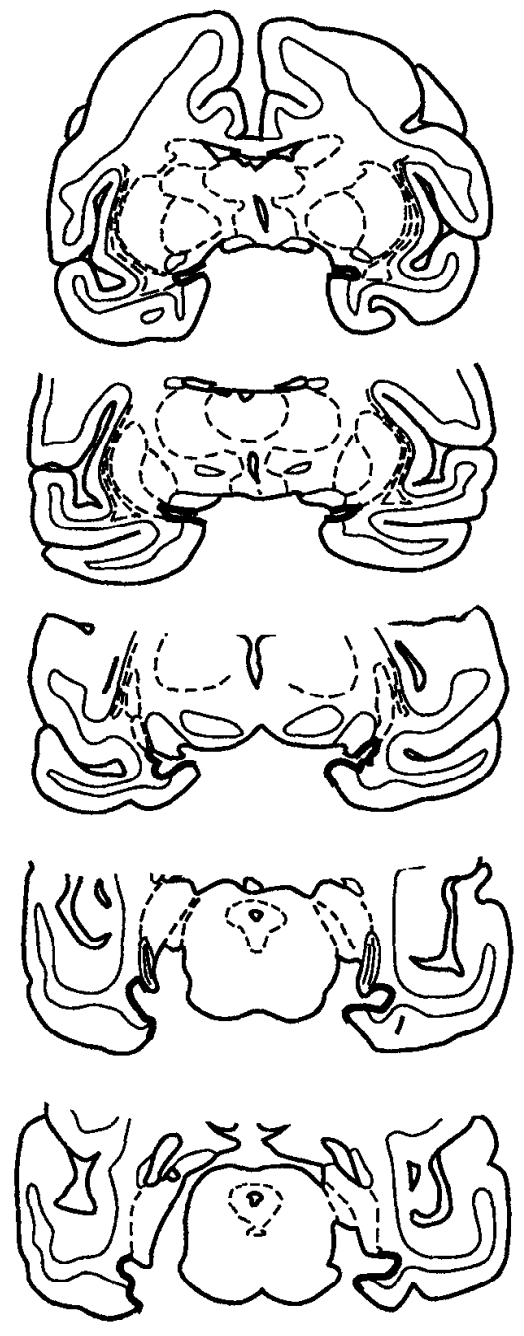

Figure 4. Ventral surface reconstruction (top) and coronal sections through the lesion (below) for one monkey with a combined ablation of the amygdala and hippocampus $(A H-3)$. The intended removal is shown in the left column. Conventions are as in Figure 2. per day. Criterion for progression from one version to the next was set at 3 consecutive days of $90 \%$ correct responses.

Stage 2. Now the monkeys were required to match a compound stimulus (sample) to one of its parts (choice test). A typical trial from this stage is illustrated in the middle panel of Figure 1. The 10 stimuli that were used in the final version of delayed matching-to-sample in stage 1 were again paired randomly to form ten 10-trial blocks. This time, however, although the whole stimulus appeared as the sample, as before, only one of the two component ASCII characters appeared for choice. Training proceeded at the rate of 100 trials per day. Criterion was maintained at $90 \%$ correct responses for 3 consecutive days.

Stage 3. The same 10 compound stimuli were employed as in stage 2. A typical trial from this stage is illustrated in the right panel of Figure 1. Now either part of one of the $\mathbf{1 0}$ stimuli appeared as the sample, and the other part of that stimulus appeared as the correct choice. The distractor on the choice test was a part of one of the other nine compound stimuli. Note that, on each choice test, the items available for choice had, on average, equivalent reward histories, so stimulus-reward association could not guide the animal's response. Criterion was the same as before. On attaining criterion, the monkeys were assigned to four groups that were balanced for the total number of sessions required to complete the three stages of preoperative training.

\section{Postoperative training}

Retention of set 1 . Ten to $19 \mathrm{~d}$ following surgery, or after an equivalent rest period for the unoperated controls, monkeys were tested for retention of the preoperatively learned paired associates (set 1 ). Training was identical to the final stage preoperatively, and the criterion was also the same. Monkeys that failed to relearn set 1 were given remedial training in delayed matching-to-sample (as in stage 1 of preoperative training) before being returned to the paired associate task. 


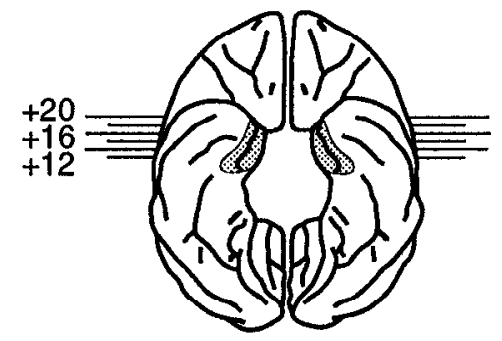

Intended Lesion
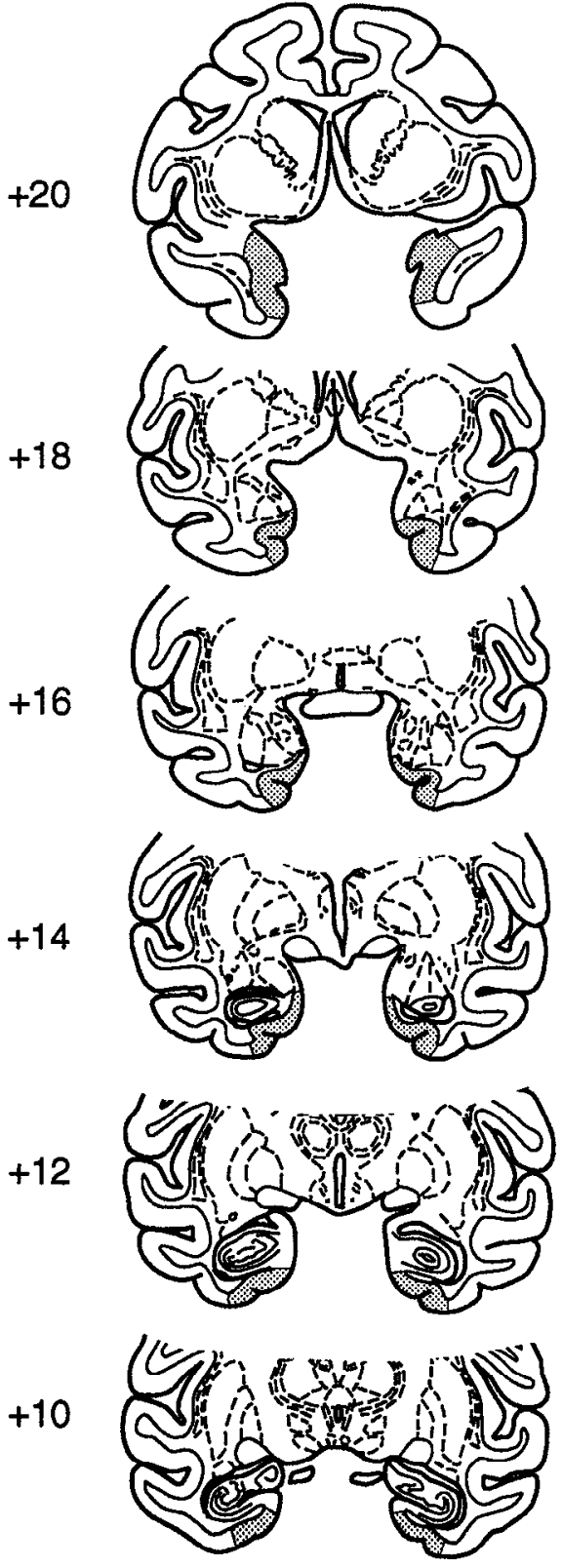
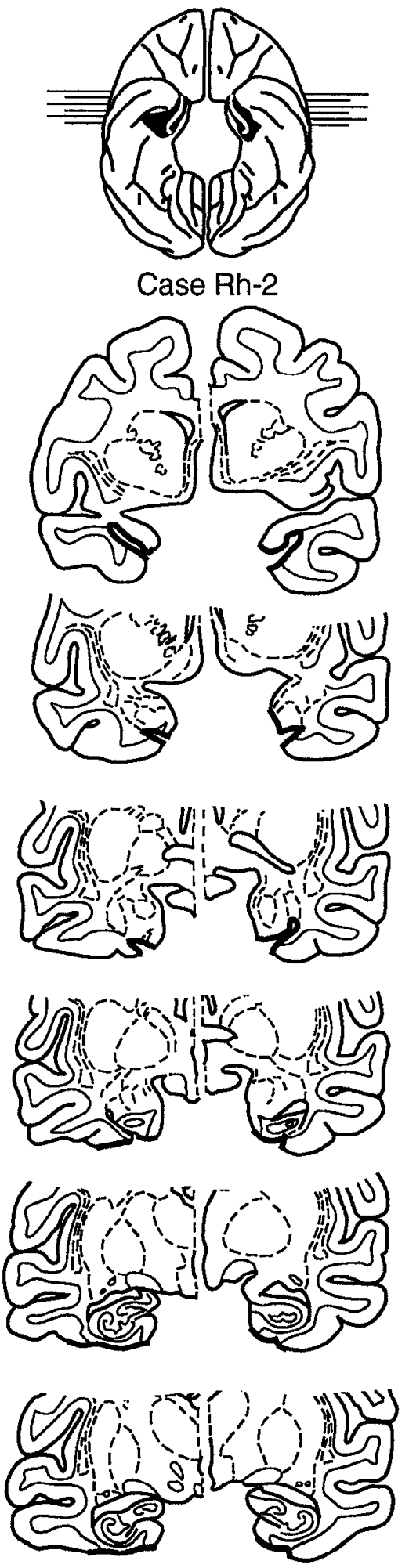

Figure 5. Ventral surface reconstruction (top) and coronal sections through the lesion (below) in one monkey with a rhinal cortical ablation $(R h-2)$. The intended removal is shown in the left column. Conventions are as in Figure 2
Acquisition of five new pairs in set 1 . To determine whether monkeys would be able to learn new paired associates without going through all the stages used preoperatively, half the already-learned stimulus pairs were discarded, and the remaining ones were mixed with five new stimulus pairs within each session. Apart from this introduction of new stimuli, testing procedures were identical to those used in stage 3 of preoperative training.

Acquisition of sets 2 and 3. Monkeys were trained successively on two new sets of stimuli (sets 2 and 3), each with 10 paired associates. Pro- cedures were identical to those used in stage 3 of preoperative training Monkeys that could not learn set 2 did not receive further testing.

Performance on set 3 with increased delays. Monkeys that learned set 3 were tested on this set with progressively longer delays between sample and choice test. The original delay of $0.5 \mathrm{sec}$ was doubled at each step, resulting in delays of $1 \mathrm{sec}$, then $2,4,8,16,32$, and, finally, $64 \mathrm{sec}$. Monkeys were tested for $2 \mathrm{~d}$ ( 200 trials) at each delay. For this phase only, the intertrial intervals were increased from $7 \mathrm{sec}$ to $15 \mathrm{sec}$.

Acquisition of set 4 (control set without part-whole learning). Monkeys 


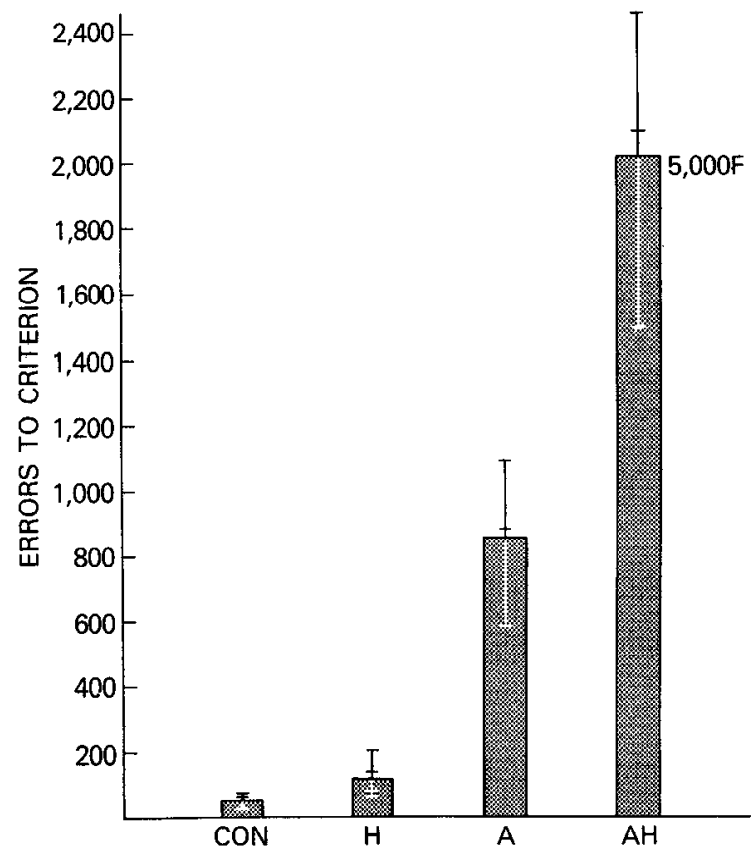

Figure 6. Errors to criterion in postoperative relearning of set 1. Height of bars indicates number of errors to relearn or, for monkeys with $\mathrm{AH}$ lesions, the number of errors accrued in 5000 trials. Tick marks on vertical bars indicate the scores of individual animals in each group. $C O N$, unoperated controls; $H$, monkeys with removals of hippocampus plus subjacent cortex; $A$, monkeys with removals of amygdala plus subjacent cortex; $A H$, monkeys with combined removals of the amygdala, hippocampus, and subjacent cortex.

were trained on a final set of 10 paired associates (set 4), but this time with a different kind of visual feedback from that used previously. Now a correct choice resulted in the reappearance of the correct stimulus directly above its original location on the side of the screen. The effect of the visual feedback was that the stimulus appeared to jump higher up on the screen. This procedure was introduced as a control for the original feedback to determine whether the monkeys had actually benefitted from the superimposition of paired associates in learning sets 1-3.

Effect of rhinal cortex ablations. The two monkeys that received ablations of the rhinal cortex after first serving as normal controls were given postoperative retraining to criterion on set 1 , in the same way as described above for the first phase of postoperative testing in the main experiment. They were then trained in a new set, set 5 , in the same way as described above for training the animals in the main experiment on sets 2 and 3 .

\section{Results}

\section{Preoperative learning}

Stage 1 . The 13 monkeys learned delayed matching-to-sample with session-unique stimuli in an average of 24 sessions (range, 9-42 sessions), comprising 1992 trials and 678 errors. The four groups that were formed did not differ from each other in any of the measures employed (number of sessions, trials, or errors to criterion) in either this or the following two preoperative stages.

Stage 2. With 10 stimuli, the monkeys learned to match the compound stimulus sample with the half-stimulus on the choice test in an average of 32 sessions (range, 15-73), comprising 3254 trials and 626 errors.

Stage 3. Two of the monkeys, $\mathrm{H}-2$ and $\mathrm{AH}-2$, could not reach the $90 \%$ criterion on this last preoperative stage but did attain $87 \%$ and $88 \%$ correct, respectively, for several weeks in a row. Using these criteria for the two animals (the same ones were

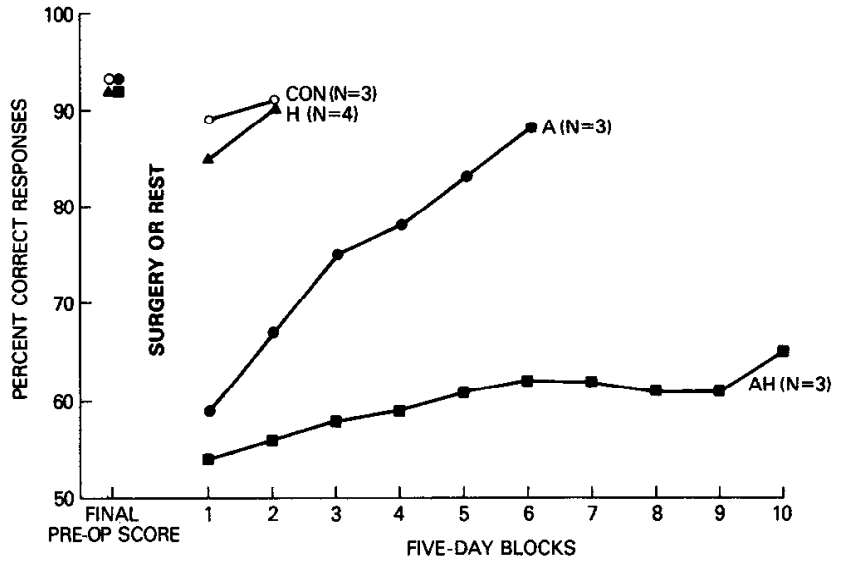

Figure 7. Postoperative relearning curves for set 1 . Mean scores by group given in $5 \mathrm{~d}$ blocks. Each point represents 500 trials per animal $x$ number of animals in group. Abbreviations are as in Figure 6 .

also used postoperatively), the 13 monkeys learned the final stage of the paired-associate task in an average of 32 sessions (range, 10-74), comprising 3208 trials and 628 errors.

\section{Postoperative retention and learning}

Retention of set 1 . The normal controls and monkeys with hippocampal removals relearned set 1 almost immediately, in an average of five and eight sessions, respectively (Figs. 6, 7). By contrast, monkeys with amygdala removals were retarded in relearning. They required a mean of 37 sessions to reattain criterion, a score that was significantly different from the scores of both the normal and hippocampectomized groups (MannWhitney $U$ test, $p<0.05$ ). Finally, all three monkeys with the combined amygdala and hippocampal removals failed to relearn the preoperatively acquired set within 50 sessions, achieving final scores of $51 \%, 79 \%$, and $65 \%$ correct responses, respectively. This group thus performed significantly more poorly ( $p$ $<0.05)$ than all the othcr groups. The animal ( $\mathrm{AH}-2)$ that scored $79 \%$ correct after 50 sessions was then trained for an additional 25 sessions, but still failed to attain criterion.

To determine whether the monkeys with combined amygdala and hippocampal removals could remember the samples, they were retrained on the original matching-to-sample task used in stage 1 preoperatively. Although other studies (Mishkin, 1978; Murray and Mishkin, 1984; Overman et al., 1990) had demonstrated that monkeys with the same extensive lesions could still perform delayed nonmatching-to-sample with short delays, the stimuli in those experiments had been objects or pictures of objects, rather than the ASCII characters used here. Nevertheless, all three monkeys succeeded in learning, two (AH-2 and $\mathrm{AH}-3)$ immediately, and the other (AH-1) after 90 training sessions. These three animals were then given further training on the first paired associate task (Fig. 8). Although AH-2 attained criterion within 15 additional scssions (i.e., $88 \%$ correct or better in each of the last 3 of the 15 sessions; see Preoperative learning, Stage 3, above), the remaining two failed in 100 additional sessions. Only one of the three monkeys (AH-1) appeared to benefit from the interpolated training on delayed matching-tosample, as shown by this animal's improvement after the remedial training sessions (see Fig. 8), yet even this improvement only increased the animal's scores to roughly the level of the other animals in this group. Cases $\mathrm{AH}-1, \mathrm{AH}-2$, and $\mathrm{AH}-3$ 


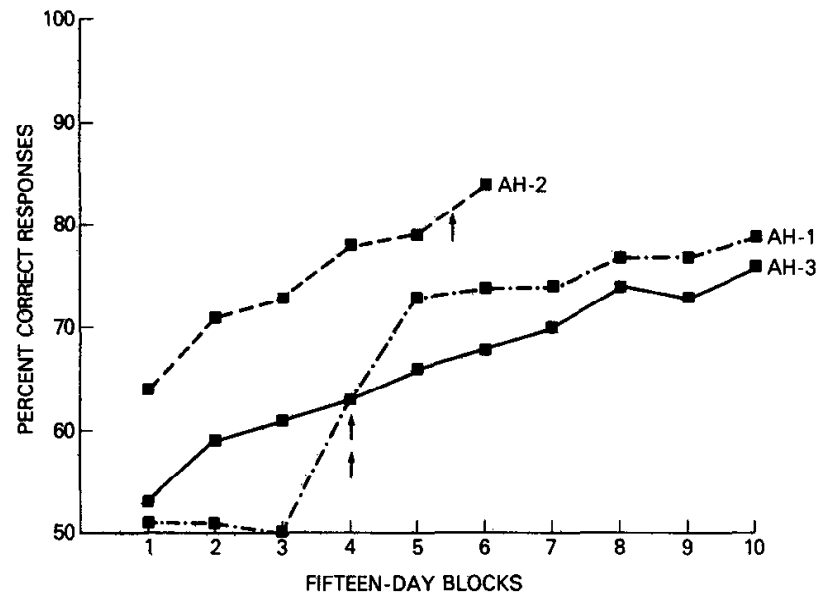

Figure 8. Postoperative relearning curves for set 1 by the three animals with combined ablations of amygdala and hippocampus. Note the difference in scale between the abscissas in Figures 7 and 8. The arrows show the point at which interpolated retraining at delayed matchingto-sample was given. For $A H-1$ and $A H-3$, block 4 consists of five sessions given before the training on delayed matching-to-sample and 10 sessions after.

achieved final scores of $79 \%, 84 \%$, and $74 \%$ correct responses, respectively, in the last block of 15 sessions with set 1 (Fig. 8), for an average of $80 \%$ correct.

Acquisition of five new pairs in set 1 . Monkeys with amygdala or hippocampal removals and the unoperated controls all learned the new pairs in a mean of 20 sessions. One monkey with the combined amygdala and hippocampal lesion (AH-2) attained criterion in 40 sessions. The remaining two monkeys in this group were given an amount of training equivalent to that received by the monkeys in the other groups ( 20 sessions) but achieved final scores of only $79 \%$ and $75 \%$ correct responses, respectively.

Acquisition of sets 2 and 3. The normal controls learned the first fully new set of 10 paired associates (set 2) in a mean of 26 sessions (range, 15-37). Monkeys with removals of either the amygdala or hippocampus learned the new pairs at a slightly slower rate, but not significantly so, attaining criterion in a mean of 53 (range, 33-86) and 28 (range, 12-65) sessions, respectively. Compared with these three groups, the monkeys with the combined amygdala and hippocampal removals were significantly retarded in learning, one (AH-2) attaining criterion in 89 sessions, and the other two failing in 100 sessions each. Over their last five sessions, monkeys $\mathrm{AH}-1$ and $\mathrm{AH}-3$ scored $73 \%$ and $70 \%$ correct responses, respectively.

The control animals learned the second new set of visualvisual paired associates (set 3 ) in a mean of 16 sessions (range, 5-31). Again, the monkeys with removals of either amygdala or hippocampus did not differ significantly from the controls in their rate of learning. The amygdalectomized animals learned in a mean of 32 sessions (range, 26-43), and the hippocampectomized animals, in a mean of 22 sessions (range, 6-55). The one monkey with the combined amygdala plus hippocampal removal that was trained at this stage $(\mathrm{AH}-2)$ required more sessions (60) to attain criterion than any of the other monkeys.

Although the groups with amygdala removals or hippocampal removals were slightly slower on average than the control animals in learning sets 2 and 3 (Fig. 9), the difference is not suggestive of a genuine effect, since it can be explained by slight

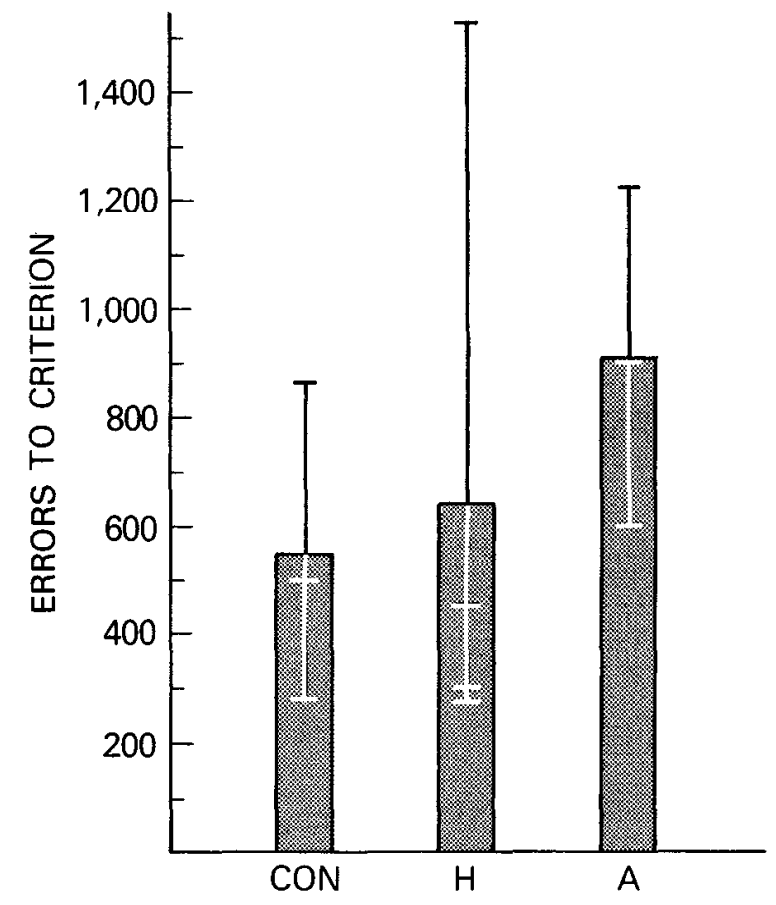

Figure 9. Mean errors to criterion in learning new postoperative sets, sets 2 and 3. Group AH is not shown because only one of these animals was tested on set 3. Conventions and abbreviations are as in Figure 6.

differences between monkeys in their preoperative learning abilities. Figure 10 shows the correlation between scores on set 1 preoperatively and those on sets 2 and 3 postoperatively. The correlation is significant $(r=0.774$, df $8, p<0.01)$, and it is evident from the figure that the relationship between preoperative and postoperative learning ability in the two operated groups was similar to that observed in the normal control group.

Performance on set 3 with increased delays. Figure 11 shows the results on set 3 when progressively longer delays were introduced between sample presentation and choice test. The scores of animals with amygdala or hippocampal removals did not differ from the scores of the controls. The one monkey with the combined amygdala and hippocampal lesion that was tested at this stage (AH-2, not shown) performed much more poorly, achieving scores of only $91 \%, 87 \%, 81 \%, 81 \%$, and $69 \%$ correct for delays up through $8 \mathrm{sec}$. This animal was not tested beyond the $8 \mathrm{sec}$ delay condition.

Acquisition of set 4 (control set without part-whole learning). In this phase only, the visual feedback for a correct choice consisted of the chosen paired associate "jumping" higher up on the screen, rather than of the appearance of the whole, or compound stimulus, as in earlier phases of training. Figure 12 compares the rate of learning of the paired associates with wholestimulus feedback (set 3 ) and the rate of learning with the "jumping" stimulus feedback (set 4). For each animal, the learning rate was much faster with the whole-stimulus feedback.

Effect of rhinal cortex ablation. Of the two normal control animals that received rhinal cortex ablations at the end of the main experiment, Rh-1 relearned set 1 to criterion in 15 sessions with 280 errors, and Rh-2 did so in 50 sessions with 1135 errors. Neither reached criterion on the new set 5 , although both were performing between $80 \%$ and $90 \%$ correct at the end of training. Training was terminated for Rh-1 after 140 sessions and 3045 errors, and for Rh-2 after 110 sessions and 2170 errors. These 


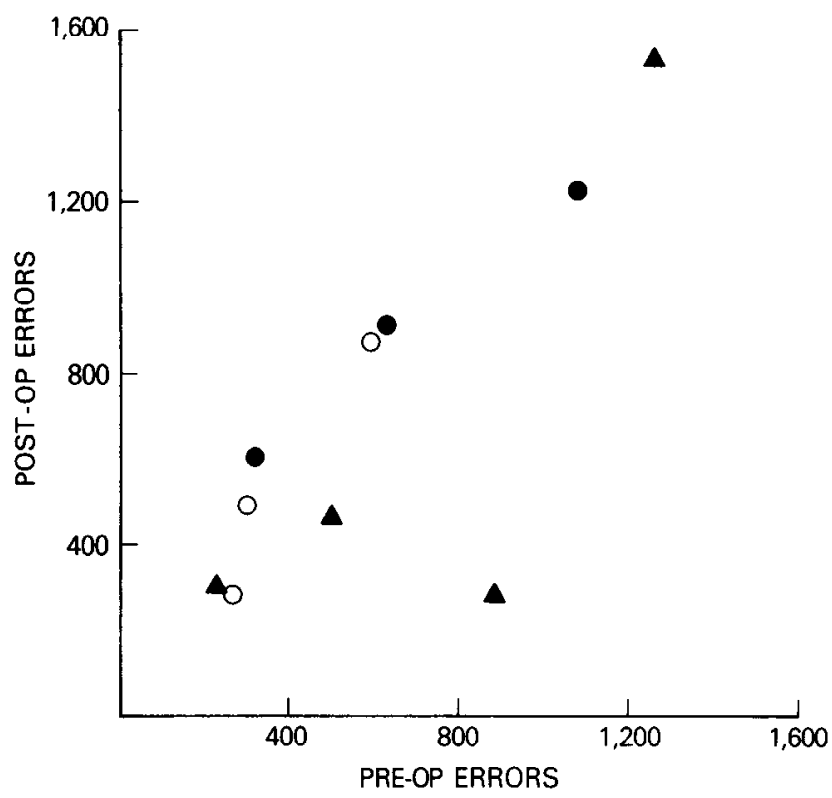

Figure 10. The correlation between errors to criterion in preoperative learning (set 1, stage 3) and postoperative learning (sets 2 and 3). Open circles show individual animals from the control group; solid circles, the amygdalectomized group; triangles, the hippocampectomized group.

scores on learning new paired associates are similar to those of the animals with combined amygdalectomy and hippocampectomy (see Figs. 6, 8). Since the latter lesions also included portions of the rhinal cortex, the question arises as to whether the similarity in behavioral outcome could have been due to this commonality in the lesions. In an attempt to answer this question, we measured the amount of rhinal cortex damage sustained by all the animals in the study (see Table 1). The analysis shows, first, that the rhinal cortex damage sustained by the monkeys with the combined amygdala and hippocampal ablations was close to the sum, in both locus and extent, of that sustained by the animals with the separate removals. Further, the percentage of damage to entorhinal cortex in the group with the combined ablations was roughly the same as that in the group with rhinal cortex lesions. However, the percentage of damage to perirhinal cortex in the two groups was markedly different (an average of $11 \%$ in group $\mathrm{AH}$ as compared to $96 \%$ in group $\mathrm{Rh}$ ). The possibility that amygdalectomy, in particular, results in additional, indirect, damage to perirhinal cortex is discussed below.

\section{Discussion}

\section{Effect of visual feedback}

The task used in the present experiment was designed to test the animals' memory for associations between the two separable parts of compound visual stimuli. In sets 1-3 the animals may have responded correctly at choice trials on the basis of memory for the compound stimulus elicited by each part, the compound stimulus having been displayed as feedback for correct choices. The normal animals (and also those with amygdalectomy or hippocampectomy) learned the correct associations between sample and choice stimuli more rapidly with this procedure than they did with a control procedure (set 4), in which they never saw the compound stimuli (Fig. 12). This aspect of the results strongly supports the idea that in sets $1-3$ the animals had indeed used memory of the association between parts of a whole stimulus to help guide their choices. The whole-stimulus

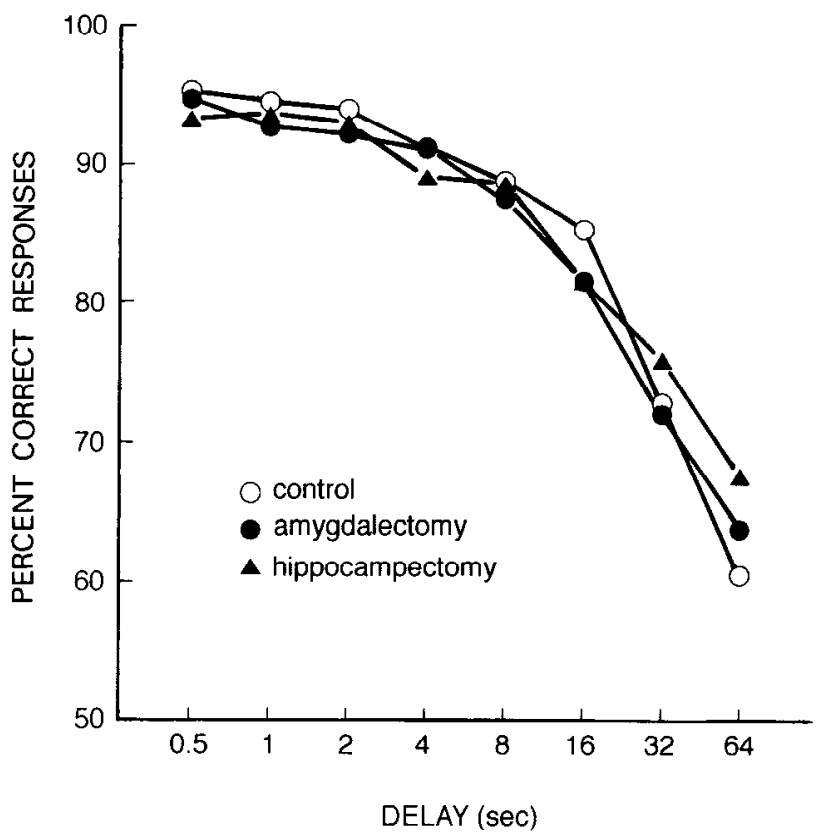

Figure 11. Performance with set 3 when the delay between the sample presentation and choice test was increased.

visual feedback was nevertheless not essential for learning new paired associates. Further, because the one monkey with a combined amygdala and hippocampal lesion that was tested on both sets 3 and 4 (AH-2; not illustrated in Fig. 12) showed the same benefit as the others from the whole-stimulus feedback, type of feedback did not appear to interact with the effect of the lesion.

\section{Effect of amygdalectomy}

Monkeys with removal of the amygdala plus subjacent cortex were impaired in postoperative retention of the preoperatively acquired set 1 (Fig. 6). This impairment was transient, however, for after the amygdalectomized monkeys relearned set 1 to criterion they subsequently learned sets $2-4$ without impairment (Figs. 9, 10, 12). Like the result from the study of Gaffan et al. (1989), indicating that amygdalectomy produced no impairment in associating visual stimuli with a local visual secondary reinforcer, the present results help rule out a possible generalization from earlier findings that the amygdala is critical for associating stimuli within a modality. These negative results on intramodal association suggest instead that the associative memory impairments seen previously after amygdalectomy, such as the loss of cross-modal association (Murray and Mishkin, 1985) and the impairment in associating visual stimuli with either a primary reinforcer (Spiegler and Mishkin, 1981; Gaffan and Murray, 1990) or an auditory secondary reinforcer (Gaffan and Harrison, 1987), may reflect a selective role for the amygdala in associating stimuli from different modalities. An alternative possibility, with which the present results are also compatible, is that the amygdala is specifically important for associating stimuli with primary reinforcement (Gaffan, 1992a).

The impairment of the amygdalectomized animals in postoperative retention of set 1 is possibly attributable to the inclusion of the anterior part of the rhinal cortex in the amygdala ablations. The anterior part of the entorhinal cortex was deliberately included, and even though the perirhinal cortex was not (see Fig. 2, Table 1), it is possible that perirhinal cortex was damaged indirectly. It has been suggested (Murray, 1992) that 


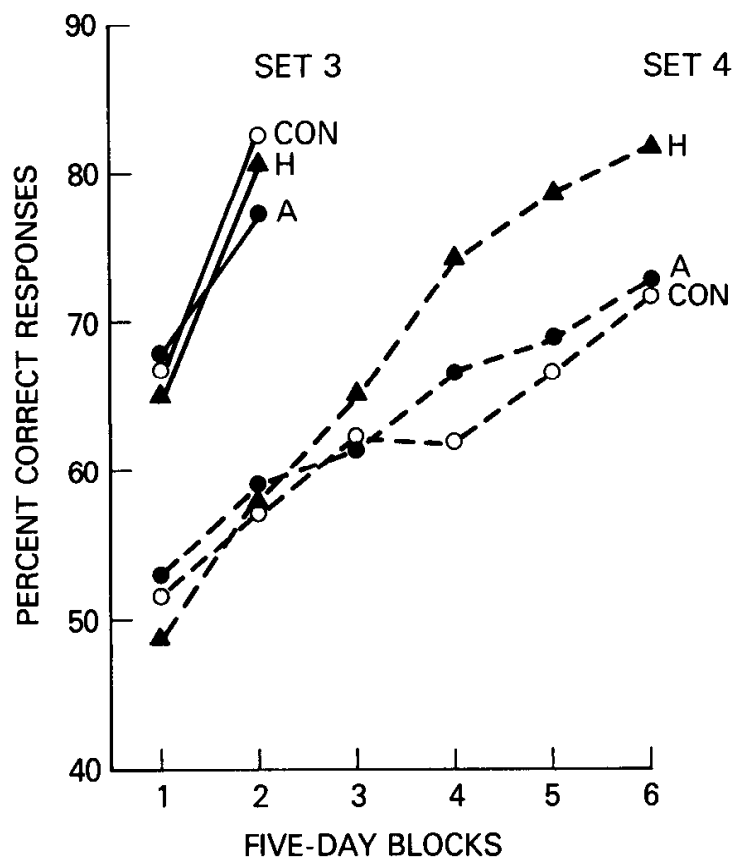

Figure 12. A comparison between learning with whole-stimulus feedback (SET 3) and learning without whole-stimulus feedback (SET 4). There were no group differences in learning within sets, but there was a significant effect across sets. The one monkey with a combined ablation of the amygdala and hippocampus that was tested on both sets 3 and 4 (AH-2) showed the same effect, achieving scores of $54 \%$ and $64 \%$ correct responses for the initial two test blocks with set 3 , and $45 \%$ and $64 \%$ for the first and sixth blocks with set 4 . Abbreviations are as in Figure 6.

efferent fibers of the perirhinal cortex passing by the lateral aspect of the amygdala are likely transected during an aspiration lesion of the amygdala. If so, perhaps this partial damage to rhinal cortex (rostral entorhinal cortex, directly, and rostral perirhinal cortex, indirectly) was sufficient to disrupt the preoperatively acquired stimulus-stimulus associations, but insufficient to disrupt the learning of new visual-visual associations. Whether the deficit is specific to retention, or is a transient effect overcome by practice or with time, cannot be determined from the present evidence. The role of the rhinal cortex in performance on the present task is discussed further below, in the sections Effect of amygdalectomy and hippocampectomy combined and Effect of rhinal cortex lesions.

\section{Effect of hippocampectomy}

Removal of the hippocampus plus subjacent cortex was without effect in the present experiment. The failure of hippocampectomy to affect retention of stimulus-stimulus associations (Figs. $6,7)$, the learning of new stimulus-stimulus associations (Figs. 9,10 ), or the ability of monkeys to choose paired associates correctly after long delays (Fig. 11) argues against the suggestions that the hippocampus is generally important for associative learning (Sutherland and Rudy, 1989; Eichenbaum et al., 1992), or that the hippocampus is critical for storing or retrieving memories during a period of consolidation (Squire et al., 1989). The present results are consistent with the idea that the hippocampal formation is specifically important for integrating stimuli in a spatial array or a complex scene (Parkinson et al., 1988; Gaffan, 1992b; Angeli et al., 1993), as opposed to associating two discrete stimulus items.

\begin{tabular}{llll}
\hline $\begin{array}{l}\text { Table 1. Percentage of rhinal cortex damage averaged for the two } \\
\text { hemispheres }\end{array}$ & PRh & Rh \\
Monkey & ERh & 0.8 & 17.5 \\
\hline A-1 & 34.2 & 6.1 & 23.5 \\
A-2 & 40.9 & 29.5 & 37.3 \\
A-3 & 44.9 & 12 & 26 \\
Mean & 40 & 1.1 & 12 \\
H-1 & 22.8 & 0.3 & 15.2 \\
H-2 & 30.1 & 2.2 & 28.4 \\
H-3 & 54.4 & 4.1 & 20.5 \\
H-4 & 36.7 & 2 & 19 \\
Mean & 36 & 7.7 & 44.7 \\
AH-1 & 81.4 & 3.4 & 36.1 \\
AH-2 & 68.6 & 20.8 & 58.6 \\
AH-3 & 96.2 & 11 & 46 \\
Mean & 82 & 95.2 & 84.8 \\
Rh-1 & 74.4 & 97.2 & 83.6 \\
Rh-2 & 70.2 & 96 & 84 \\
Mean & 72 &
\end{tabular}

Measures were obtained (in each hemisphere separately) by plotting the lesions on a set of standard coronal sections at $1 \mathrm{~mm}$ intervals, outlining the extent of the lesion on each section with a digitizer (Jandel, Inc.) to obtain the surface area, calculating the volume of damaged tissue across sections, and comparing it to the entire extent of rhinal cortex in the standard. The volumes of entorhinal cortex (ERh) and perirhinal cortcx (PRh) in the intact rhesus monkey are almost identical, so the percentage of damage to the rhinal cortex $(\mathrm{Rh})$ within an individual is approximated by the mean of the percentage damage to the two components. Note that subjects A-3 and AH-3, the monkeys with the most damage to perirhinal cortex in their respective groups (but the most damage to the tail of caudate nucleus as well), had the poorest postoperative scores overall in their groups.

\section{Effect of amygdalectomy and hippocampectomy combined}

The impairment found in the present study in the animals with the combined ablations was evident in both relearning and new learning. In relearning, this group attained a final mean score of only $80 \%$ correct after receiving an average of 20 times as many sessions as that required by the normal and hippocampectomized groups to learn. Similarly, in new learning (of set 2 ), two of the three monkeys in this group could not attain criterion even after receiving roughly four times as many sessions as that required by the normal and hippocampectomized monkeys. In learning five new pairs, the first postoperative stage in which the ability to learn new associations was assessed, these two animals with the combined lesions were given only an amount of training equivalent to that received by animals in other groups, rather than training to criterion. Perhaps their failure to reach criterion in both relearning set 1 and learning 5 new pairs (set 1) contributed to their later difficulty in learning 10 new pairs (set 2). Nevertheless, it is clear that all three animals in the combined lesion group were by far the most severely affected animals in the main part of the study.

The pattern of impairment after separate and combined ablations of the amygdala and hippocampus in the present study is strikingly similar to that seen previously in delayed nonmatching-to-sample (Mishkin, 1978; Murray and Mishkin, 1984). In both delayed nonmatching-to-sample and the present tasks, a severe impairment followed the combined ablation, although ablation of either limbic structure alone produced either no impairment or only a mild impairment. There are now at least two different interpretations possible for this pattern of 
deficits. First, although neither the amygdala alone nor the hippocampus alone is essential for either stimulus recognition or intramodal stimulus-stimulus associative memory, this could be because each structure can serve the function in the absence of the other. If so, then impairment would ensue, as here, only when damage to the two structures is combined. The second possibility, which has already been referred to, relates to the role of the rhinal cortex. Whereas the separate amygdala and hippocampal removals each were associated with damage to about $35-40 \%$ of the entorhinal cortex, the combined aspiration lesions of the amygdala and hippocampus resulted in roughly twice this amount of damage (Table 1). In addition to the relatively small amount of inadvertent damage to the perirhinal cortex (associated mainly with the amygdala removal), there is the potential at least for extensive damage to critical efferents from the perirhinal cortex projecting to regions outside the medial temporal lobe (see Effect of amygdalectomy, above). Although we have no way to measure the amount of indirect damage caused by fiber transection, the group with combined ablations of the amygdala and hippocampus clearly sustained more extensive damage to the rhinal cortex (i.e., both the entorhinal and perirhinal cortex), on average, than did the other two groups. Thus, the combined damage to entorhinal and perirhinal cortex, rather than the combined ablation of the amygdala and hippocampus, could be responsible for the impairment. This is so becausc delibcratc lesions of perirhinal plus entorhinal cortex, leaving the amygdala and hippocampus intact, now have been shown to produce severe losses in recognition memory (Gaffan and Murray, 1992; Meunier et al., 1993).

\section{Effect of rhinal cortex lesions}

In the present study, the two normal control animals that later received rhinal cortex ablations showed an impairment similar in severity to that produced in the main experiment by combined amygdalectomy and hippocampectomy. It should be pointed out, however, that the evidence demonstrating the importance of the rhinal cortex for both recognition and associative memory does not rule out a major contribution to these functions from the amygdala and hippocampus. Only by conducting studies in which these two structures are removed in combination without concomitant damage to the rhinal cortex can their role in memory be definitively ascertained.

\section{Nature of the impairment}

The task we used in the present experiment requires the monkey at each choice trial to apply two different memories. That is, the animal must remember the sample presented $0.5 \mathrm{sec}$ earlier, and must also remember the association with that sample of one of the choice stimuli, an association that the animal has slowly learned over many trials. In principle, therefore, the deficit following combined ablations of amygdala and hippocampus, and, equally, the deficit following rhinal cortex ablations alone, could result from an impairment in either one of these two memories, or in both. In fact, however, we can rule out the first possibility because the monkeys with the combined ablation were able to perform delayed matching-to-sample with the same visual stimuli and at the same short delay $(0.5 \mathrm{sec})$ as in the associative task. Further, after extensive postoperative retraining with one set of stimuli (set 1; Fig. 8) these animals finally scored an average of $80 \%$ correct choices on that set, yet failed new sets. Our data thus indicate that monkeys with combined lesions were able to retain a sample in memory for $0.5 \mathrm{sec}$, but were severely retarded in learning visual-visual associations.

This interpretation of the nature of the impairment is supported by recent electrophysiological evidence. Sakai and Miyashita (1991) recorded the activity of single cells in the inferior temporal cortex of monkeys performing a task that was modeled on the task we used in the present experiment. The neuronal activity was influenced in two ways by the visual paired associates the animals had learned. First, some cells that showed maximal activity in response to a particular stimulus also showed an increase in activity when that stimulus was expected, that is, in the delay period following presentation of its paired associate. Second, some cells responded in a similar way to the two members of a paired associate; the correlation between the activity elicited by each member of the pair, presented separately, was greater than expected by chance. Thus, Sakai and Miyashita's results show that cellular activity in the inferior temporal cortex reffects the animals' visual associative memory, and not simply the physical properties of the visual stimuli. The recordings were taken from the temporal neocortex surrounding the anterior middle temporal sulcus, in a region that overlapped substantially with the area included in our rhinal cortex lesion. Sakai and Miyashita suggested that the neurons they recorded from might serve as memory storage elements. Taken together, our results and those of Sakai and Miyashita implicate the medial temporal lobe, and particularly the rhinal cortex, in the formation of stimulus-stimulus associative memories.

\section{References}

Angeli SJ, Murray EA, Mishkin M (1993) Hippocampectomized monkeys can remember one place but not two. Neuropsychologia, in press.

Baylis LL, Gaffan D (1991) Amygdalectomy and ventromedial prefrontal ablation produce similar deficits in food choice and in simple object discrimination learning for an unseen reward. Exp Brain Res 86:617-622.

Eichenbaum H, Otto T, Cohen NJ (1992) The hippocampus-what does it do? Behav Neural Biol 57:2-36.

Gaffan D (1992a) Amygdala and the memory of reward. In: The amygdala: neurobiological aspects of emotion, memory, and mental dysfunction (Aggleton JP, ed), pp 471-483. New York: Wiley-Liss.

Gaffan D (1992b) Amnesia for complex naturalistic scenes and for objects following fornix transection in the rhesus monkey. Eur $\mathbf{J}$ Neurosci 4:381-388.

Gaffan D, Bolton J (1983) Learning of object-object associations by monkeys. Q J Exp Psychol 35B:149-155.

Gaffan D, Harrison S (1987) Amygdalectomy and disconnection in visual learning for auditory secondary reinforcement by monkeys. $J$ Neurosci 7:2285-2292.

Gaffan D, Harrison S (1989) Place memory and scene memory: effects of fornix transection in the monkey. Exp Brain Res 74:202-212.

Gaffan D, Murray EA (1990) Amygdalar interaction with the mediodorsal nucleus of the thalamus and the ventromedial prefrontal cortex in stimulus-reward associative learning in the monkey. $J$ Neurosci 10:3479-3493.

Gaffan D, Murray EA (1992) Monkeys (Macaca fascicularis) with rhinal cortex ablations succeed in object discrimination learning despite $24-\mathrm{hr}$ intertrial intervals and fail at matching to sample despite double sample presentations. Behav Neurosci 106:30-38.

Gaffan D, Saunders RC (1985) Running recognition of configural stimuli by fornix-transected monkeys. Q J Exp Psychol 37B:61-71.

Gaffan D, Saunders RC, Gaffan EA, Harrison S, Shields C, Owen MJ (1984) Effects of fornix transection upon associative memory in monkeys: role of the hippocampus in learned action. Q J Exp Psychol 36B: $173-221$.

Gaffan D, Gaffan EA, Harrison S (1989) Visual-visual associative learning and reward-association learning in monkeys: the role of the amygdala. J Neurosci 9:558-564.

Gaffan EA, Gaffan D, Harrison S (1988) Disconnection of the amyg- 
dala from visual association cortex impairs visual reward-association learning in monkeys. J Neurosci 8:3144-3150.

Horel JA, Pytko-Joiner DE, Voytko ML, Salsbury K (1987) The performance of visual tasks while segments of the inferotemporal cortex are suppressed by cold. Behav Brain Res 23:29-42.

Meunier M, Bachevalier J, Mishkin M, Murray EA (1993) Effects on visual recognition of combined and separate ablations of the entorhinal and perirhinal cortex in rhesus monkeys. $J$ Neurosci, in press.

Mishkin M (1978) Memory in monkeys severely impaired by combined but not by separate removal of amygdala and hippocampus. Nature 273:297-298.

Murray EA (1992) Medial temporal lobe structures contributing to recognition memory: the amygdaloid complex versus the rhinal cortex. In: The amygdala: neurobiological aspects of emotion, memory, and mental dysfunction (Aggleton JP, ed), pp 453-470. New York: Wiley-Liss.

Murray EA, Mishkin M (1984) Severe tactual as well as visual memory deficits follow combined removal of the amygdala and hippocampus in monkeys. J Neurosci 4:2565-2580.

Murray EA, Mishkin M (1985) Amygdalectomy impairs crossmodal association in monkeys. Science 228:604-606.
Overman WH, Ormsby G, Mishkin M (1990) Picture recognition vs. picture discrimination learning in monkcys with medial temporal removals. Exp Brain Res 79:18-24.

Parkinson JK, Murray EA, Mishkin M (1988) A selective mnemonic role for the hippocampus in monkeys: memory for the location of objects. J Neurosci 8:4159-4167.

Sakai K, Miyashita Y (1991). Neural organization for the long-term memory of paired associates. Nature 354:152-155.

Spiegler BJ, Mishkin M (1981) Evidence for the sequential participation of inferior temporal cortex and amygdala in the acquisition of stimulus-reward associations. Behav Brain Res 3:303-317.

Squire LR, Shimamura AP, Amaral DG (1989) Memory and the hippocampus. In: Neural models of plasticity (Byrne J, Berry W, eds), pp 208-239. New York: Academic.

Sutherland RJ, Rudy JW (1989) Configural association theory: the role of the hippocampal formation in learning, memory, and amnesia. Psychobiology 17:129-144.

Zola-Morgan S, Squire LR, Amaral DG, Suzuki WA (1989) Lesions of perirhinal and parahippocampal cortex that spare the amygdala and hippocampal formation produce severe memory impairment. $\mathrm{J}$ Neurosci 9:4355-4370. 